\title{
Oral findings in children and adolescents with Prader-Willi syndrome
}

\author{
Dorota Olczak-Kowalczyk $^{1}$ (D) Emil Korporowicz ${ }^{1} \cdot$ Dariusz Gozdowski $^{2} \cdot$ Agnieszka Lecka-Ambroziak $^{3}$. \\ Mieczysław Szalecki ${ }^{3,4}$
}

Received: 2 January 2017 / Accepted: 3 July 2018 / Published online: 14 July 2018

(C) The Author(s) 2018

\begin{abstract}
Objective To assess the significance of changes in the saliva in the etiology of gingivitis and tooth wear in children and adolescents with Prader-Willi syndrome (PWS).

Materials and methods The study included 80 (2.8-18 years old; 39 girls and 41 boys): 40 in PWS group (mean age $8.0 \pm$ 4.24 years) and 40 in control group (mean age $7.9 \pm 4.12$ years). General condition, oral para-functional habits, tooth wear (modified TWI), oral hygiene and gingival status (Plaque Index (PLI) and Gingival Index (GI)), localization of gingivitis, and salivary characteristics were assessed. The chi-square test, the Mann-Whitney $U$ test, Spearman's rank correlation, and odds ratio based on logistic regression in a statistical analysis were applied.

Results Chances of gingivitis were increased by low PLI (odds ratio $(\mathrm{OR})=32.53)$, low resting salivary flow $(\mathrm{OR}=3.96)$, increased viscosity of saliva $(\mathrm{OR}=3.54)$, and mouth breathing $(\mathrm{OR}=8.17)$. For gingivitis in anterior regions, low PLI $(\mathrm{OR}=$ 107.67), low resting $(\mathrm{OR}=5.73)$ and stimulated $(\mathrm{OR}=1.86)$ salivary flow, increased viscosity of saliva $(\mathrm{OR}=5.87)$, mouth breathing $(\mathrm{OR}=10.00)$, and low stimulated salivary flow $(\mathrm{OR}=3.18)$ were observed. Tooth wear rates were increased by teeth grinding $(\mathrm{OR}=16.20)$, mouth breathing $(\mathrm{OR}=4.33)$, increased viscosity of saliva $(\mathrm{OR}=11.67)$ and low resting $(\mathrm{OR}=6.07)$, and stimulated $(\mathrm{OR}=4.22)$ salivary flow.

Conclusions In PWS, reduced salivary secretion, increased viscosity, of saliva and mouth breathing increase the risk of plaqueinduced gingivitis and tooth wear.

Clinical relevance The prevention and treatment of tooth wear and gingivitis in PWS patients is necessary not only to treat bruxism and mouth breathing but also to limit the influence of negative changes of saliva.
\end{abstract}

Keywords Prader-Willi syndrome · Gingivitis · Tooth wear

\section{Introduction}

The prevalence of Prader-Willi syndrome (PWS) is estimated at 1:10000-1:30000 births [1]. In the majority of cases (approximately $65-75 \%$ ), it is caused by de novo deletions in the region $15 \mathrm{q} 11 \mathrm{q} 13$ on the paternal chromosome and more

Dorota Olczak-Kowalczyk

do-k@o2.pl

1 Department of Pediatric Dentistry, Medical University of Warsaw, Miodowa 18, Warsaw, Poland

2 Department of Experimental Statistics and Bioinformatics, Warsaw University of Life Sciences, Nowoursynowska 159, Warsaw, Poland

3 Clinic of Endocrinology and Diabetology, Children's Memorial Health Institute, Dzieci Polskich 20, Warsaw, Poland

4 Faculty of Medicine and Health Sciences, UJK, Kielce, Poland frequently (approximately 20-30\%) by maternal disomy of chromosome 15 , sporadically other mutations in this region $[1,2]$. PWS is characterized by significant cognitive, neurological, endocrine, and behavioral abnormalities. Clinical manifestations vary depending on the genotype, age, and method of treatment. In the infancy, the predominant symptoms include hypotonia, early feeding problems, and difficulty with weight gain and hypogonadism. In older children, hypotonia often persists; however, feeding difficulties are followed by excessive eating which may lead to obesity $[1,2]$. The numerous symptoms of PWS include the following: hypothalamic hypogonadism, growth hormone insufficiency, intellectual disability, and characteristic behavior problems (e.g., temper tantrums, obsessive and compulsive behaviors, and mood fluctuations), sleep disorders (central and obstructive sleep apnea, abnormal arousal, abnormal circadian rhythm in REM sleep, reduced REM latency, and abnormal response to hypercapnia), saliva secretion disorders, and changes in 
the salivary composition and consistency [1-9]. Many phenotypic features of PWS may favor oral cavity disorders. In PWS, mouth breathing, poor oral hygiene [10,11], and bruxism are often observed [6]. Predisposition to dental caries [10-13], enamel defects $[10,11,14-16]$, tooth wear [6, 17], gingivitis [5], lesions on the oral mucous membrane, especially self-injured lesions, candidiasis, and angular cheilitis have been reported [8].

It is generally known that low salivary flow and high viscosity of saliva are important caries risk factors in patients with PWS. There also seems to exist the correlation between salivary physical-chemical parameters in these patients and lesions on the oral mucous membrane [8] and tooth wear [6]. However, there is no detailed information on the significance of individual salivary parameters in the development of these pathologies. Changes associated with saliva may also play a role in the pathogenesis of gingivitis in patients with PWS, as they may increase the susceptibility of periodontal tissues to bacteria and favor accumulation of the dental plaque.

The aim of the study was to assess the significance of changes in the saliva in the etiology of gingivitis and tooth wear in children and adolescents with Prader-Willi syndrome (PWS).

\section{Material and methods}

\section{Patients}

The study included 80 patients at the age between 2.5 and 17.2 years (41 boys and 39 girls): 40 with Prader-Willi syndrome (PWS group) reporting for their routine checkups at Clinic of Endocrinology and Diabetology, Children's Memorial Health Institute, and 40 healthy individuals (controls) reporting for their checkups at the Department of Paediatric Dentistry, Warsaw Medical University. Studies were performed after a written consent of the patients and/or their parents/legal guardians. Bioethics committee had been obtained. The control group was age- and sex-matched to the
PWS group. Exclusion criteria from both groups were as follows: lack of cooperation with the dentist, cigarette smoking, and orthodontic treatment. Patients with obesity and chronic diseases or who are receiving chronic treatment were excluded from the control group, whereas patients with gastroesophageal reflux disease were excluded from the PWS group.

Table 1 presents characteristics of patients with regard to the type of dentition. Thirty-nine patients with PWS were included in the National Health Service (NHS) Growth Hormone Program (the inclusion criteria were rehabilitation, lack of obesity $<97$ centile, low-calorie diet, balanced carbohydrate metabolism, absence of other contraindications to growth hormone therapy). One patient with PWS was obese. Obesity was not present in the control group.

\section{Method}

A case-control study was performed in a dental office and included an analysis of medical documentation and an interview with the patient and/or parents/legal guardians (presence of systemic diseases, applied medicinal products, oral parafunctional habits), dental examination, and assessment of physical and chemical parameters. General health status of PWS patients was assessed by a pediatrician from the Clinic of Endocrinology and Diabetology.

The study was conducted by two dental surgeons with clinical experience in children dentistry longer than 5 years, after the Cohen's kappa coefficient was calibrated and the value of 0.8 was achieved. The following were assessed: teeth grinding and mouth breathing, presence of tooth wear, hygiene status according to the Silness and Löe Plaque Index and gingival status according to Gingival Index with regard to six index teeth: $16,12,24,36,32$, and 44 (in the deciduous dentition: $55,51,63,75,71$, and 83 ), localization of gingivitis, and presence of periodontal pockets [18]. Pocket depths (only around permanent first molars and incisors) were recorded for children over the age of 12 . The WHO 621 probe with a $0.5-\mathrm{mm}$ ball end and black band at 3.5 to $5.5 \mathrm{~mm}$ was used [19].
Table 1 Characteristics of patients with Prader-Willi syndrome and the control group

\begin{tabular}{|c|c|c|c|c|}
\hline Parameters & & & PWS & Control group \\
\hline \multirow[t]{8}{*}{ Type of dentition } & Deciduous & $N$ & 18 & 18 \\
\hline & & Mean age \pm SD (years) & $49.8 \pm 12.8$ & $49.4 \pm 9.1$ \\
\hline & Mixed & $N$ & 15 & 15 \\
\hline & & Mean age \pm SD (years) & $102.0 \pm 20.7$ & $103.5 \pm 14.4$ \\
\hline & Permanent & $N$ & 8 & 8 \\
\hline & & Mean age \pm SD (years) & $171.3 \pm 26.1$ & $174.9 \pm 25.7$ \\
\hline & Total & $N$ & 41 & 41 \\
\hline & & Mean age \pm SD (years) & $92.6 \pm 49.3$ & $93.6 \pm 49.6$ \\
\hline \multirow[t]{2}{*}{ Sex } & Female & $\mathrm{N}$ & 20 & 20 \\
\hline & Male & & 21 & 21 \\
\hline
\end{tabular}


The presence of tooth wear was assessed on the labial, incisal, and palatal/lingual surfaces of the six upper and lower anterior teeth and on the occlusal surfaces of all four permanent first molars (mixed and permanent dentition) or second primary molars (deciduous dentition). Surfaces were scored in accordance with the Smith and Knight Tooth Wear Index modified by Bardsley et al. [20, 21]. Dentine exposure (score 1 - the dentine is just visible (including cupping) or dentine exposure of less than a third of the surface, and score 2dentine exposure greater than a third of the surface) and exposure of pulp or secondary dentine (score 3-exposure of pulp or secondary dentine) were taken into account. Injuries due to orthodontic appliances and surfaces destroyed by dental caries or with fillings were not included.

The Saliva-Check Buffer Test, GC Co., Tokyo, Japan, was used for saliva tests $[8,22,23]$. The assessment was done according to the manufacturer's instruction. Saliva tests were performed in the morning at least $2 \mathrm{~h}$ after breakfast. Patients did not brush their teeth or use a mouthwash for at least $1 \mathrm{~h}$. The following elements are assessed:

- Resting flow rate (the moistening rate of the lower lip mucosa): the time for visible production of saliva $>60 \mathrm{~s}$ - low resting salivary rate;

- Visual assessment of salivary consistency: 1-watery clear (normal viscosity), 2-frothy bubbly (increased viscosity), 3-sticky frothy (increased viscosity);

- $\mathrm{pH}$ of resting saliva by checking the color of the strip in collection cup with expectorated unstimulated saliva: highly acidic saliva with $\mathrm{pH}$ 5.0-5.8, moderately acidic saliva with $\mathrm{pH}$ 6.0-6.6, and normal acidic saliva with pH 6.8-7.8;

- Stimulated salivary flow: normal with $>5 \mathrm{ml} / 5 \mathrm{~min}$, low with 3.5-5.0 ml/5 min, and very low with $<3.5 \mathrm{ml} / 5 \mathrm{~min}$;

- Buffering ability of stimulated saliva: normal (10-12 pkt), low (6-9 pkt), or very low (0-5 pkt), according to the pad color.

Saliva secretion was stimulated by chewing paraffin tablets. Every $30 \mathrm{~s}$, patients were asked to expectorate the saliva into a graduated test tube. Saliva was being collected for exactly $5 \mathrm{~min}$.

\section{Statistical analysis}

Comparison of percentages for binomial variables between two groups was performed using chi-square test. Means of quantitative variables were compared based on the MannWhitney $U$ test. Spearman's rank correlation coefficient was used for evaluation of relationships between pairs of variables. Odds ratio (OR) and confidence interval (CI) for OR based on logistic regression were calculated for selected pairs of variables. The analyses were conducted using Statistica 12
(StatSoft) and SPSS Statistics 23 (IBM). The L=level of significance for all analyses was set at 0.05 .

\section{Results}

Table 2 presents results of a clinical examination and physicalchemical parameters of the saliva in PWS and control groups. Table 3 includes the mean values and SD of salivary parameters ( $\mathrm{pH}$ of resting saliva, $\mathrm{pH}$ of resting saliva, and buffering ability of stimulated saliva) and Plaque Index (PLI) and Gingival Index (GI) in both groups and with regard to the type of dentition. Tooth wear with pulp exposure (score 3) and severe gingivitis (GI > 2.1) and periodontal pockets (probing depths $\geq 3.5 \mathrm{~mm}$ ) were not observed in any of subjects. Poor hygiene status (PLI > 1.9) was observed in four (10.0\%) subjects in the control group and $16(40.0 \%)$ patients with PWS.

Stimulated salivary flow was not assessed in eight patients (three children with PWS and five in the control group) as they finished paraffin chewing too early. A photograph (Fig. 1) presents tooth wear and gingivitis in child with PWS.

The Spearman correlation analysis performed for the whole group showed a positive correlation between the patient's age and the GI score $(r=0.226 ; p<0.05)$ and the presence of tooth wear $(r=0.371 ; p<0.05)$. Moreover, a correlation between teeth grinding and mouth breathing was also shown $(r=0.508 ; p<0.05)$ and between teeth grinding and salivary parameters such as the moistening rate of the lower lip mucosa $(r=-0.403 ; p<0.05)$ and watery consistency of saliva $(r=-$ $0.380 ; p<0.05)$. Table 4 presents statistically significant correlations between salivary parameters, hygiene status of the oral cavity, teeth grinding, and mouth breathing with parameters describing gingival status and tooth wear. The odds ratios (OR), calculated for all patients, are included in Table 5.

A logistic regression method confirmed the effects of salivary parameters on the accumulation of the dental plaque. The PLI values higher than 1.9 were favored by low resting salivary flow $(\mathrm{OR}=10.11$ (CI 2.95-34.66); $p<0.001)$, increased viscosity of saliva $(\mathrm{OR}=5.23(\mathrm{CI} 1.56-17.52) ; p=0.007), \mathrm{pH}$ of resting salivary flow $<6(\mathrm{OR}=3.66(1.27-10.55) ; p=$ $0.016)$, and very low stimulated salivary flow $(\mathrm{OR}=10.23$ (CI 1.28-81.87); $p=0.028)$.

\section{Discussion}

Our study confirmed worse physical and chemical parameters of saliva in subjects with PWS compared to the control group, which is consistent with reports of other authors [3-8]. Additionally, a negative correlation between the age of PWS patients and watery consistency of saliva was observed, and it suggests that the salivary viscosity may increase with age. Similarly to other researchers, we observed a predisposition 
Table 2 The prevalence of changes in the saliva, gingivitis, tooth wear, teeth grinding, and mouth breathing in PWS group and in the control group
Table 3 Mean values and SD of salivary parameters, PLI, and GI in PWS and control groups and with regard to the type of dentition

\begin{tabular}{|c|c|c|c|c|c|}
\hline Tested parameters & $N(\%)$ & All patients & $\begin{array}{l}\text { Group with } \\
\text { PWS }\end{array}$ & $\begin{array}{l}\text { Control } \\
\text { group }\end{array}$ & $p$ \\
\hline \multirow[t]{2}{*}{ Resting flow rate } & $<60 \mathrm{~s}$ & $47 / 80(58.7)$ & $7 / 40(17.5)$ & $40 / 40(100)$ & $<0.001 *$ \\
\hline & $>60 \mathrm{~s}$ & $33 / 80(41.3)$ & $33 / 40(82.5)$ & $0 / 40(0.0)$ & $<0.001 *$ \\
\hline \multirow[t]{3}{*}{ Salivary consistency } & Watery clear & $38 / 80(47.5)$ & $1 / 40(2.5)$ & $37 / 40(92.5)$ & $<0.001 *$ \\
\hline & Frothy bubbly & $13 / 80(16.3)$ & $12 / 40(30.0)$ & $1 / 40(2.5)$ & $0.001 *$ \\
\hline & Sticky frothy & $29 / 80(36.3)$ & $27 / 40(67.5)$ & $2 / 40(5.0)$ & $<0.001 *$ \\
\hline \multirow[t]{3}{*}{$\mathrm{pH}$ of resting saliva } & $5.0-5.8$ & $20 / 80(25.0)$ & $20 / 40(50.0)$ & $0 / 40(0.0)$ & $<0.001 *$ \\
\hline & $6.0-6.6$ & $24 / 80(30.0)$ & $19 / 40(47.5)$ & $5 / 40(12.5)$ & $<0.001 *$ \\
\hline & $6.8-7.8$ & $36 / 80(45.0)$ & $1 / 40(2.5)$ & $35 / 40(87.5)$ & $<0.001 *$ \\
\hline \multirow{3}{*}{$\begin{array}{l}\text { Stimulated salivary flow } \\
\qquad(\mathrm{ml} / 5 \mathrm{~min})\end{array}$} & $<3.5$ & $34 / 80(42.5)$ & $30 / 37(81.1)$ & 4/35 (11.4) & $<0.001 *$ \\
\hline & $3.5-5.0$ & $35 / 80(43.8)$ & $7 / 37(18.9)$ & $28 / 35(80.0)$ & $<0.001 *$ \\
\hline & $>5.0$ & $3 / 80(3.8)$ & $0 / 37(0.0)$ & $3 / 35(8.6)$ & 0.069 \\
\hline \multirow{3}{*}{$\begin{array}{l}\text { Buffering ability of } \\
\text { stimulated saliva }\end{array}$} & Very low & $11 / 80(13.8)$ & $10 / 40(25.0)$ & $1 / 40(5.0)$ & $0.003 *$ \\
\hline & Low & $31 / 80(38.8)$ & $22 / 40(55.0)$ & $9 / 40(22.5)$ & $0.003^{*}$ \\
\hline & Normal & $38 / 80(47.5)$ & $8 / 40(20.0)$ & $30 / 40(75.0)$ & $<0.001 *$ \\
\hline \multicolumn{6}{|l|}{ Clinical examination } \\
\hline \multicolumn{2}{|l|}{ Mouth breathing } & $10 / 80(12.5)$ & $9 / 40(12.5)$ & $1 / 40(2.5)$ & $0.007 *$ \\
\hline \multicolumn{2}{|l|}{ Teeth grinding (bruxism) } & $11 / 80(13.8)$ & $11 / 40(27.5)$ & $0 / 40(0.0)$ & $<0.001 *$ \\
\hline \multicolumn{2}{|l|}{ Tooth wear (score 1 and 2) } & $24 / 80(30.0)$ & $19 / 40(47.5)$ & $5 / 40(12.5)$ & $<0.001 *$ \\
\hline \multirow[t]{2}{*}{ Gingivitis $(\mathrm{GI}>0.1)$} & & $31 / 80(38.8)$ & $22 / 40(55.0)$ & $9 / 40(22.5)$ & $0.003 *$ \\
\hline & $\begin{array}{l}\text { Only in maxillary } \\
\text { and mandibular } \\
\text { anterior regions }\end{array}$ & 9/80 (11.3) & $8 / 40(20.0)$ & $1 / 40(2.5)$ & $0.013^{*}$ \\
\hline
\end{tabular}

* Statistical significance $p<0.05$

\begin{tabular}{lllcc}
\hline Parameters & & PWS & Control group & $p$ \\
\hline Deciduous dentition & pH of resting saliva & $5.97 \pm 0.46$ & $7.11 \pm 0.31$ & $<0.001^{*}$ \\
& Stimulated salivary flow (ml/5 min) & $2.30 \pm 1.35$ & $3.97 \pm 0.74$ & 0.001 \\
& Buffering ability of stimulated saliva & $6.82 \pm 2.83$ & $10.41 \pm 1.58$ & $<0.001^{*}$ \\
& GI & $0.12 \pm 0.19$ & $0.04 \pm 0.15$ & 0.144 \\
& PLI & $1.11 \pm 0.71$ & $0.74 \pm 0.54$ & 0.104 \\
& pH of resting saliva & $5.91 \pm 0.38$ & $7.03 \pm 0.38$ & $<0.001^{*}$ \\
& Stimulated salivary flow (ml/5 min) & $1.50 \pm 1.07$ & $4.17 \pm 1.18$ & $<0.001^{*}$ \\
& Buffering ability of stimulated saliva & $6.87 \pm 2.36$ & $10.4 \pm 1.50$ & $<0.001^{*}$ \\
& GI & $0.71 \pm 0.74$ & $0.24 \pm 0.43$ & $0.043^{*}$ \\
& PLI & $1.71 \pm 0.95$ & $1.32 \pm 0.68$ & 0.210 \\
& pH of resting saliva & $5.94 \pm 0.43$ & $7.04 \pm 0.47$ & $<0.001^{*}$ \\
& Stimulated salivary flow (ml/5 min) & $2.31 \pm 1.19$ & $4.36 \pm 0.97$ & $0.002^{*}$ \\
& Buffering ability of stimulated saliva & $6.75 \pm 3.01$ & $9.50 \pm 1.93$ & $0.047^{*}$ \\
& GI & $0.56 \pm 0.81$ & $0.14 \pm 0.23$ & 0.177 \\
& PLI & $1.56 \pm 1.13$ & $0.81 \pm 0.60$ & 0.119 \\
& pH of resting saliva & $5.94 \pm 0.42$ & $7.06 \pm 0.36$ & $<0.001^{*}$ \\
& Stimulated salivary flow (ml/5 min) & $2.00 \pm 1.25$ & $4.15 \pm 0.98$ & $<0.001^{*}$ \\
& Buffering ability of stimulated saliva & $6.83 \pm 2.63$ & $10.23 \pm 1.62$ & $<0.001^{*}$ \\
& GI & $0.45 \pm 0.65$ & $0.13 \pm 0.30$ & $0.007^{*}$ \\
& PLI & $1.43 \pm 0.92$ & $0.97 \pm 0.65$ & $0.014^{*}$ \\
\hline \multirow{3}{*}{ All group } & & & & \\
& & &
\end{tabular}

*Statistically significant differences between PWS and control groups at 0.05 probability level 


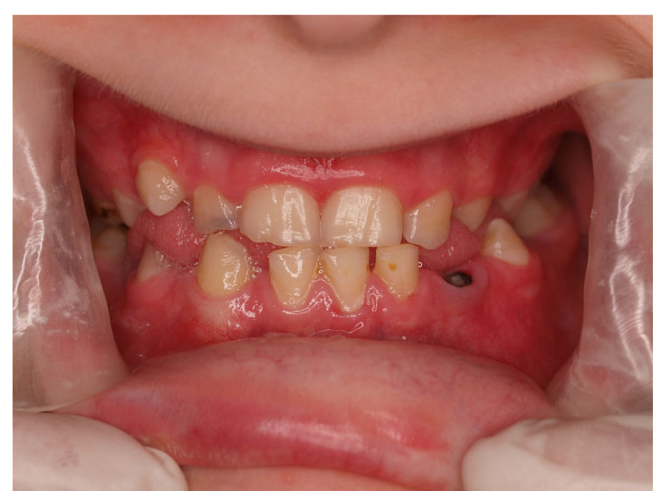

Fig. 1 Tooth wear and gingivitis in the anterior section of the mandible and maxilla in child with PWS in the deciduous dentition

to tooth wear in PWS patients [6]. Moreover, we demonstrated a tendency to accumulation of the dental plaque and gingivitis in this group of patients.

\section{Tooth wear}

Teeth grinding is the main etiological factor of tooth wear. However, in our study, this symptom was reported more rarely than tooth wear. In the studies by Saeves et al. in a group of 49 patients with PWS at the age of 6.5-40.9 years, the frequency of teeth grinding in PWS (36.7\%) was also lower than tooth wear $(89.8 \%$ ) [6]. It seems that the incidence of teeth grinding was underestimated by parents of subjects. PWS patients often suffer from sleep apnea and they have emotional and behavioral problems, e.g., overeating, difficulty with routine change, temper tantrums, mood fluctuations, aggression, and auto-aggression. These factors are suggested to be involved in the precipitation of bruxism [24]. On the other hand, higher prevalence of tooth wear compared to teeth grinding may emphasize the importance of others factors, e.g., exposure of teeth tissues to acid. However, Saeves et al. did not confirm a significant correlation between tooth wear and obesity, sex, and consumption of acid beverages. In their opinion, PWS patients suffer from persistent hunger and a consequent urge to eat. When they are given access to soft drinks, it is therefore unlikely that drinking of the beverage is spread over time. This may go some way towards explaining the lack of association between high consumption of acid drinks and erosive wear [6]. Thirty-nine out of the 40 patients we examined were in the NHS Growth Hormone Program and followed a lowcalorie diet. Seaves et al., however, observed that the intensity of tooth wear increased with age and it was associated with the reduced secretion of saliva [6]. According to our results, both salivary flow and salivary consistency seem to be important factors. Ramsay et al., likewise, confirmed a higher risk of significant tooth wear in subjects with reduced stimulated salivary flow and with thick, sticky, or frothy saliva [25]. These authors also showed that significance of these parameters was reduced when other risk factors of tooth wear were simultaneously taken into account.

It is known that impaired capability to dilute and neutralize acids increases acid effects on teeth, and consequently, the susceptibility to mechanical factors. Our results suggest that tooth wear may be favored by lower buffering ability of stimulated saliva and higher acidity of resting saliva. Nonetheless, significance of these parameters was not confirmed by a logistic regression analysis. Certainly, worse salivary quality and reduced amount of saliva both play important roles in the etiology of tooth wear [26]. Our observations are consistent with results of studies that confirm the effects of reduced salivary flow and its $\mathrm{pH}$ on the dental erosion rate [24, 26, 27]. However, a relationship with buffering capacity needs to be explained further due to contradictory reports. A relationship between lower buffering capacity and tooth wear $[28,29]$ and the lack of such a relationship [30-32] were both demonstrated.

The relationship between teeth grinding and mouth breathing and lower secretion of saliva is also worth noticing. However, this relationship is not clearly demonstrated, as

Table 4 Spearman correlation coefficients (r) between the hygiene status of the oral cavity, gingivitis and tooth wear and physical-chemical parameters of saliva, mouth breathing and teeth grinding

\begin{tabular}{|c|c|c|c|c|c|}
\hline & PLI & GI & $\begin{array}{l}\text { Presence of gingivitis } \\
(\mathrm{GI}>0.1)\end{array}$ & $\begin{array}{l}\text { Gingivitis in maxillary/ } \\
\text { mandibular anterior regions }\end{array}$ & Tooth wear \\
\hline Resting salivary flow - the time & $-0.496^{*}$ & $-0.427 *$ & $-0.424 *$ & $-0.397 *$ & $-0.393 *$ \\
\hline Salivary consistency —increased viscosity & $0.365^{*}$ & $0.419^{*}$ & $0.408^{*}$ & $0.383^{*}$ & $0.459 *$ \\
\hline Resting salivary $\mathrm{pH}$ & $-0.368^{*}$ & $-0.409 *$ & $-0.399 *$ & $-0.372 *$ & $-0.233 *$ \\
\hline Stimulated salivary flow $\mathrm{ml} / 5 \mathrm{~min}$ & $-0.331 *$ & $-0.361 *$ & $-0.340 *$ & $-0.346^{*}$ & $-0.300 *$ \\
\hline Salivary buffering capacity — the number of points & $-0.310^{*}$ & $-0.410 *$ & $-0.398 *$ & $-0.312^{*}$ & $-0.346^{*}$ \\
\hline Hygiene of the oral cavity_PLI (value) & - & $0.742 *$ & $0.702 *$ & $0.722^{*}$ & $0.248 *$ \\
\hline Mouth breathing & 0.198 & 0.217 & $0.336^{*}$ & $0.357^{*}$ & $0.247 *$ \\
\hline Teeth grinding & $0.275^{*}$ & $0.252 *$ & $0.372 *$ & $0.392 *$ & $0.451 *$ \\
\hline
\end{tabular}

*Statistical significance $p<0.05$ 
Table 5 Odds ratios (OR) between the gingivitis and tooth wear and physical-chemical parameters of saliva, hygiene status of the oral cavity, mouth breathing, and teeth grinding for all group of patients (N/\% - number/percentage of patients with bad outcome)

\begin{tabular}{|c|c|c|c|c|}
\hline \multicolumn{2}{|l|}{ Parameters } & \multirow{2}{*}{$\begin{array}{l}\text { Presence of gingivitis } \\
(\mathrm{GI}>0.1)\end{array}$} & \multirow{2}{*}{$\begin{array}{l}\text { Gingivitis in maxillary/ } \\
\text { mandibular anterior regions }\end{array}$} & \multirow[t]{2}{*}{ Tooth wear } \\
\hline$N / \%$ & & & & \\
\hline \multicolumn{5}{|l|}{ Resting salivary flow } \\
\hline \multirow[t]{3}{*}{ Low salivary flow } & Yes & $19 / 33(57.6 \%)$ & $19 / 33(57.6 \%)$ & $17 / 33(51.5 \%)$ \\
\hline & No & $12 / 47(25.5 \%)$ & $9 / 47(19.1 \%)$ & $7 / 47(14.9 \%)$ \\
\hline & OR & $\begin{array}{l}3.96(95 \% \mathrm{CI}=1.53-10.26) \\
\quad p=0.005^{*}\end{array}$ & $\begin{array}{l}5.73(95 \% \mathrm{CI}=2.10-15.61) \\
\quad p<0.001 *\end{array}$ & $\begin{array}{l}6.07(95 \% \mathrm{CI}=2.11-17.42) \\
p<0.001 *\end{array}$ \\
\hline \multicolumn{5}{|l|}{ Salivary consistency } \\
\hline \multirow[t]{3}{*}{ Increased viscosity } & Yes & $22 / 42(52.4 \%)$ & $22 / 42(52.4 \%)$ & $21 / 42(50.0 \%)$ \\
\hline & No & $9 / 38(23.7 \%)$ & $6 / 38(15.8 \%)$ & $3 / 38(7.9 \%)$ \\
\hline & OR & $\begin{array}{l}3.54(95 \% \mathrm{CI}=1.35-9.28) \\
\quad p=0.010^{*}\end{array}$ & $\begin{array}{l}5.87(95 \% \mathrm{CI}=2.03-16.96) \\
\quad p=0.001 *\end{array}$ & $\begin{array}{c}11.67(95 \% \mathrm{CI}=3.10-43.90) \\
p<0.001^{*}\end{array}$ \\
\hline \multicolumn{5}{|l|}{ Resting salivary $\mathrm{pH}$} \\
\hline \multirow[t]{3}{*}{$\mathrm{pH}<6$} & Yes & $10 / 20(50.0 \%)$ & $10 / 20(50.0 \%)$ & $7 / 20(35.0 \%)$ \\
\hline & No & $21 / 60(35.0 \%)$ & $18 / 60(30.0 \%)$ & $17 / 60(28.3 \%)$ \\
\hline & OR & $\begin{array}{l}1.86(95 \% \mathrm{CI}=0.67-5.17) \\
\quad p=0.236\end{array}$ & $\begin{array}{l}2.33(95 \% \mathrm{CI}=0.83-6.57) \\
\quad p=0.109\end{array}$ & $\begin{array}{l}1.36(95 \% \mathrm{CI}=0.46-4.00) \\
\quad p=0.574\end{array}$ \\
\hline \multicolumn{5}{|c|}{ Stimulated salivary flow } \\
\hline \multirow[t]{3}{*}{$<3.5 \mathrm{ml} / 5 \mathrm{~min}$} & YES & $18 / 34(52.9 \%)$ & $17 / 34(50.0 \%)$ & $16 / 34(47.1 \%)$ \\
\hline & NO & $13 / 46(28.3 \%)$ & $11 / 46(23.9 \%)$ & $8 / 46(17.4 \%)$ \\
\hline & OR & $\begin{array}{l}2.86(95 \% \mathrm{CI}=1.13-7.24) \\
\quad p=0.027^{*}\end{array}$ & $\begin{array}{l}3.18(95 \% \mathrm{CI}=1.23-8.26) \\
\quad p=0.018^{*}\end{array}$ & $\begin{array}{l}4.22(95 \% \mathrm{CI}=1.53-11.68) \\
\quad p=0.006^{*}\end{array}$ \\
\hline \multicolumn{5}{|c|}{ Salivary buffering capacity } \\
\hline \multirow[t]{3}{*}{ Low or very low } & Yes & $7 / 11(63.6 \%)$ & $6 / 11(54.5 \%)$ & $4 / 11(36.4 \%)$ \\
\hline & No & $24 / 69(34.8 \%)$ & $22 / 69(31.9 \%)$ & $20 / 69(29.0 \%)$ \\
\hline & OR & $\begin{array}{l}3.2895 \% \mathrm{CI}=(0.87-12.34) \\
\quad p=0.079\end{array}$ & $\begin{array}{l}2.56(95 \% \mathrm{CI}=0.71-9.31) \\
\quad p=0.152\end{array}$ & $\begin{array}{l}1.40(95 \% \mathrm{CI}=0.36-5.31) \\
\quad p=0.621\end{array}$ \\
\hline \multicolumn{5}{|c|}{ Hygiene of the oral cavity } \\
\hline \multirow[t]{3}{*}{ PLI $\geq 1.9$} & Yes & $18 / 20(90.0 \%)$ & $19 / 20(95.0 \%)$ & $9 / 20(45.0 \%)$ \\
\hline & No & $13 / 60(21.7 \%)$ & $9 / 60(15.0 \%)$ & $15 / 60(25.0 \%)$ \\
\hline & OR & $\begin{array}{l}32.53(95 \% \\
\quad \mathrm{CI}=6.67-158.72) \\
p<0.001 *\end{array}$ & $\begin{array}{l}107.67(95 \% \mathrm{CI}=12.77-907.93) \\
\quad p<0.001 *\end{array}$ & $\begin{array}{l}2.45(95 \% \mathrm{CI}=0.85-7.06) \\
\quad p=0.096\end{array}$ \\
\hline \multirow[t]{6}{*}{ Mouth breathing } & Yes & $8 / 10(80 \%)$ & $8 / 10(80.0 \%)$ & $6 / 10(60.0 \%)$ \\
\hline & No & $23 / 32.9 \%$ & $20 / 28.6 \%$ & $18 / 80(25.7 \%)$ \\
\hline & OR & $\begin{array}{l}8.17(95 \% \mathrm{CI}=1.61-41.63) \\
\quad p=0.011^{*}\end{array}$ & $\begin{aligned} 10.00 & (95 \% \mathrm{CI}=1.95-51.24) \\
p & =0.006^{*}\end{aligned}$ & $\begin{array}{l}4.33(95 \% \mathrm{CI}=1.09-17.12) \\
\quad p=0.036^{*}\end{array}$ \\
\hline & Yes & & & $9 / 11(81.8 \%)$ \\
\hline & No & & & $15 / 21.7 \%$ \\
\hline & OR & - & - & $\begin{array}{l}16.20(95 \% \mathrm{CI}=3.16-83.14) \\
\quad * p<0.001\end{array}$ \\
\hline
\end{tabular}

*Statistical significance $p<0.05$

reduction of salivary flow is observed in subjects with bruxism [33]. It is also known that sleep-related reduction of salivary flow is a normal physiological process and rhythmic masticatory muscle activity (RMMA) during sleep may stimulate salivary secretion and may play an important role in lubricating the oral cavity. In subjects with sleep bruxism (SB), RMMA is more common and more intense compared to healthy subjects [34]. It is possible that in subjects with reduction of salivary flow, such as PWS patients, dried oroesophageal tissues promote the mechanism of saliva secretion via stimulation of the masticatory muscles during the night [35]. Mouth breathing is also associated with bruxism as it facilitates respiration [36, 37]. PWS patients are predisposed to sleep-disordered breathing due to a 
combination of characteristic craniofacial features, obesity, hypotonia, and hypothalamic dysfunction. In the post-infant period, more than $80 \%$ of PWS patients suffer from obstructive sleep apnea (OSA) [38].

\section{Gingivitis}

Limited number of studies showed the predisposition to diseases of gingival and periodontal tissues in PWS. In the studies by Saeves et al., the median GI rates in the PWS group were $0.29(0.06-0.65)$ and $0.17(0.04-0.25)$ in the control group [5]. There were also reports of cases presenting periodontitis in a 20-year-old male patient [39] and a 13-year-old female patient [40]. Our PWS patients were susceptible to gingivitis but we did not see any clinical symptoms of periodontitis.

All authors highlighted the significance of both bad hygienic habits and mouth breathing in the etiology of gingivitis in these patients $[5,39,40]$. A tendency to chronic inflammation due to overactivation of the innate immune system in PWS might also be a contributing factor [41].

Our results confirm that the presence of the dental plaque is a significant factor causing gingivitis. However, changes in the salivary parameters are also important, as they contribute to more difficult teeth cleaning and they modify living conditions for bacteria. Reduction of salivary flow and saliva consistency other than watery favors accumulation of the dental plaque and gingivitis. In PWS group with mixed dentition, the mean value of GI was significantly higher than in the control group. At the same time, there was not a significant difference between mean values of PLI while the mean value of stimulated salivary flow was the highest of all groups. Interpretation of the results for the group with primary dentition is more difficult because of the lower gingival reaction to bacterial irritation in early childhood [42]. On the other hand, in permanent dentition groups, the influence of sex hormones should be taken into consideration. Hypogonadism is a constant feature in PWS and a cause of delayed or incomplete puberty of both males and females. Despite low testosterone levels in boys and low estradiol levels in girls with PWS, the mean value of GI was higher than in control group, though the difference was not statistically significant $[1,2,43]$.

In case of gingivitis located in the anterior regions of the mandible and maxilla, mouth breathing also seems to be significant risk factor. It is known that chronic mouth breathing can cause localized gingivitis of the exposed gingiva in the maxillary and mandibular labial area. Gingival margins are rolled and interdental papillae are bulbous and enlarged. It indicates persisting inflammation in this area. Some authors also emphasize a relationship between mouth breathing and the GI value in children and it is consistent with our results [44]. On the other hand, in their studies with children between the age of 8 and 12 years, Piva et al. observed no correlation between gingivitis and mouth breathing [45].
There are various views on the relationship between gingivitis associated with mouth breathing and accumulation of the dental plaque $[44,46]$. It was demonstrated, however, that stimulated saliva in patients who breathe through the mouth shows higher levels of free sialic acid, and it favors greater load of bacteria in the oral cavity [47]. Our studies confirmed that mouth breathing favors their presence on the teeth surfaces, but it has to be noted that a method applied to assess the hygiene status on index teeth was not completely reflected the effects of mouth breathing on the level of the dental plaque on labial surfaces of the anterior teeth. Nonetheless, salivary parameters, especially low salivary flow and increased viscosity of saliva, turned out to be important with regard to the etiology of gingivitis associated with mouth breathing.

\section{Conclusion}

In PWS patients, reduced salivary secretion and increased viscosity of saliva increase the risk of plaque induced gingivitis and tooth wear. In prevention and treatment of them, it is necessary not only to treat bruxism and mouth breathing but also to limit the influence of negative changes of saliva. Stimulation of salivary secretion by using a topical fluorides or/and application of sugar-free gum might be very helpful in this group of patients. Chewing gums containing both xylitol and CPP-ACP could be particularly suitable, because use of xylitol leads to considerable reductions of cariogenic bacteria and caries incidence in children, while availability of the CPP$\mathrm{ACP}$ enhance the remineralization process.

\section{Compliance with ethical standards}

Conflict of interest The authors declare that they have no conflict of interest.

Ethical approval The study was approved by the Bioethics Committee, Medical University of Warsaw, No. KB/92/2015.

Informed consent Informed consent was obtained from all individual participants included in the study.

Open Access This article is distributed under the terms of the Creative Commons Attribution 4.0 International License (http:// creativecommons.org/licenses/by/4.0/), which permits unrestricted use, distribution, and reproduction in any medium, provided you give appropriate credit to the original author(s) and the source, provide a link to the Creative Commons license, and indicate if changes were made.

\section{References}

1. Cassidy SB, Schwartz S, Miller JL, Driscoll DJ (2012) Prader-Willi syndrome. Genet Med 14(1):10-26. https://doi.org/10.1038/gim. 0b013e31822bead0 
2. McCandless SE, THE COMMITTEE ON GENETICS (2011) Clinical report-health supervision for children with Prader-Willi syndrome. Pediatrics 127(1):195-204. https://doi.org/10.1542/ peds. $2010-2820$

3. Hart PS (1998) Salivary abnormalities in Prader-Willi syndrome. Ann N Y Acad Sci 15:125-131

4. Saeves R, Reseland JE, Kvam BM, Sandvik L, Nordgarden H (2012) Saliva in Prader-Willi syndrome: quantitative and qualitative characteristics. Arch Oral Biol 57(10):1335-1341. https://doi. org/10.1016/j.archoralbio.2012.05.003.

5. Saeves R, Nordgarden H, Storhaug K, Sandvik L, Espelid I (2012) Salivary flow rate and oral findings in Prader-Willi syndrome: a case-control study. Int J Paediatr Dent 22(1):27-36. https://doi.org/ 10.1111/j.1365-263X.2011.01153.x

6. Saeves R, Espelid I, Storhaug K, Sandvik L, Nordgarden H (2012) Severe tooth wear in Prader-Willi syndrome. A case-control study. BMC Oral Health 28(12):12. https://doi.org/10.1186/1472-6831-12-12

7. Gonzales LC, Villa CG, Cardenas AC (2008) Prader-Willi syndrome: saliva quantification and culture in 10 patients. Med Oral Patol Oral Cir Bucal 13(12):E774-E777

8. Olczak-Kowalczyk D, Witt A, Gozdowski D, GinalskaMalinowska M (2011) Oral mucosa in children with Prader-Willi syndrome. J Oral Pathol Med 40:778-784. https://doi.org/10.1111/ j.1600-0714.2011.01034.x

9. Yee BJ, Buchanan PR, Mahadev S et al (2001) Assessment of sleep and breathing in adults with Prader-Willi syndrome: a case control series. J Clin Sleep Med 3(7):713-718

10. Bots CP, Schueler YT, Brand HS, van Nieuw AA (2004) A patient with Prader-Willi syndrome. Characteristics, oral consequences and treatment options. Ned Tijdschr Tandheelkd 111(2):55-58

11. Scardina GA, Fuca G, Messina P (2007) Oral diseases in a patient affected with Prader-Willi syndrome. Eur J Paediatr Dent 8(2):96-99

12. Bazopoulou-Kyrkanidou E, Papagiannoulis L (1992) Prader-Willi syndrome: report of a case with special emphasis on oral problems. J Clin Pediatr Dent 17(1):37-40

13. Salako NO, Ghafouri HM (1995) Oral findings in a child with Prader-Labhart-Willi syndrome. Quintessence Int 26(5):339-341

14. Anavi Y, Mintz SM (1990) Prader-Labhart-Willi syndrome. Ann Dent 49(2):26-29

15. Bassarelli V, Baccetti T, Bassarelli T, Franchi L (1991) The dentomaxillofacial characteristics of the Prader-Labhart-Willi syndrome. A clinical case report. Minerva Stomatol 40(12):811-819

16. Banks PA, Bradley JC, Smith A (1996) Prader-Willi syndrome-a case report of the multidisciplinary management of the orofacial problems. Br J Orthod 23(4):299-304

17. Young W, Khan F, Brandt R, Savage N, Razek AA, Huang Q (2001) Syndromes with salivary dysfunction predispose to tooth wear: case reports of congenital dysfunction of major salivary glands, Prader-Willi, congenital rubella, and Sjogren's syndromes. Oral Surg Oral Med Oral Pathol Oral Radiol Endod 92(1):38-48. https://doi.org/10.1067/moe.2001.113549

18. Loe H (1967) The gingival index, the plaque index and the retention index systems. J Periodontol 38:610-616

19. Clerehugh V (2008) Periodontal diseases in children and adolescents. Br Dent J 204(8):469-471. https://doi.org/10.1038/sj.bdj. 2008.301

20. Smith BG, Knight JK (1984) An index for measuring the wear of teeth. Br Dent J 156(12):435-438

21. Bardsley PF, Taylor S, Milosevic A (2004) Epidemiological studies of tooth wear and dental erosion in 14-year-old children in $r$ West England. Part 1: the relationship with water fluoridation and social deprivation. Br Dent J 197(7):413-416. https://doi.org/10.1038/sj. bdj. 4811722

22. Cheaib Z, Ganss C, Lamanda A, Turgut MD, Lussi A (2012) Comparison of three strip-type tests and two laboratory methods for salivary buffering analysis. Odontology 100:67-75. https://doi. org/10.1007/s10266-011-0018-1

23. Animireddy D, Reddy Bekkem VT, Vallala P, Kotha SB, Ankireddy S, Mohammad N (2014) Evaluation of pH, buffering capacity, viscosity and flow rate levels of saliva in caries-free, minimal caries and nursing caries children: an in vivo study. Contemp Clin Dent 5(3):324-328. https://doi. org/10.4103/0976-237X.137931

24. Shetty S, Pitti V, Satish Babu CL, Surendra Kumar GP, Deepthi BC (2010) Bruxism: a literature review. J Indian Prosthodont Soc 10(3): 141-148. https://doi.org/10.1007/s13191-011-0041-5

25. Ramsay DS, Rothen M, Scott J, Cunha-Cruz J (2015) Tooth wear and the role of salivary measures in general practice patients. Clin Oral Invest 19(1):85-95. https://doi.org/10.1007/ s00784-014-1223-4

26. Milosevic A (1998) Tooth wear: aetiology and presentation. Dent Update 25:6-11

27. Lussi A, von Salis-Marincek M, Ganss C, Hellwig E, Cheaib Z, Jaeggi $\mathrm{T}$ (2012) Clinical study monitoring the $\mathrm{pH}$ on tooth surfaces in patients with and without erosion. Caries Res 46(6):507-512. https://doi.org/10.1159/000339783

28. Holbrook WP, Furuholm J, Gudmundsson K, Theodors A, Meurman JH (2009) Gastric reflux is a significant causative factor of tooth erosion. J Dent Res 88(5):422-426

29. Correa MC, Lerco MM, de Cunha ML, Henry MA (2012) Salivary parameters and teeth erosions in patients with gastroesophageal reflux disease. Arq Gastroenterol 49(3):214-218. https://doi.org/ 10.1590/S0004-28032012000300009

30. Johansson AK, Lingstrom P, Birkhed D (2002) Comparison of factors potentially related to the occurrence of dental erosion in high-and low-erosion groups. Eur J Oral Sci 110:204-211

31. Wang P, Zhou Y, Zhu YH, Lin HC (2011) Unstimulated and stimulated salivary characteristics of 12-13-year-old schoolchildren with and without dental erosion. Arch Oral Biol 56:1328-1332. https://doi.org/10.1016/j.archoralbio.2011.04.013

32. Bartlett DW, Coward PY, Nikkah C, Wilson RF (1998) The prevalence of tooth wear in a cluster sample of adolescent schoolchildren and its relationship with potential explanatory factors. Br Dent J 184: 125-129. https://doi.org/10.1038/sj.bdj.4809560

33. Murali RV, Rangarajan P, Mounissamy A (2015) Bruxism: conceptual discussion and review. J Pharm Bioallied Sci 7:267. https://doi.org/10.4103/0975-7406.155948

34. Lavigne GJ, Rompré PH, Poirier G, Huard H, Kato T, Montplaisir JY (2001) Rhythmic masticatory muscle activity during sleep in humans. J Dent Res 80(2):443-448

35. Thie NM, Kato T, Bader G, Montplaisir JY, Lavigne GJ (2002) The significance of saliva during sleep and the relevance of oromotor movements. Sleep Med Rev 6(3):213-227. https://doi.org/10.1053/ smrv.2001.0183

36. Bektas D, Cankaya M, Livaoglu M (2011) Nasal obstruction may alleviate bruxism related temporomandibular joint disorders. Med Hypotheses 76(2):204-205. https://doi.org/10. 1016/j.mehy.2010.09.030

37. Balasubramaniam R, Klasser GD, Cistulli PA, Lavigne GJ (2014) The link between sleep bruxism, sleep disordered breathing and temporomandibular disorders: an evidence-based review. J Dent Sleep Med 1(1):27-37. https://doi.org/10.15331/jdsm.3736

38. Sedky K, Bennett DS, Pumariega A (2014) Prader-Willi syndrome and obstructive sleep apnea: co-occurrence in the pediatric population. J Clin Sleep Med 10(4):403-409. https://doi.org/10.5664/ jcsm.3616

39. Yanagita M, Hirano H, Kobashi M, Nozaki T, Yamada S, Kitamura M, Murakami S (2011) Periodontal disease in a patient with PraderWilli syndrome: a case report. J Med Case Rep. https://doi.org/10. 1186/1752-1947-5-329 
40. Greenwood RE, Small IC (1990) Case report of the Prader-Willi syndrome. J Clin Periodontol 17(1):61-63. https://doi.org/10.1111/ j.1600-051X.1990.tb01049.x

41. Viardot A, Sze L, Purtell L, Sainsbury A, Loughnan G, Smith E, Herzog H, Steinbeck K, Campbell LV (2010) Prader-Willi syndrome is associated with activation of the innate immune system independently of central adiposity and insulin resistance. J Clin Endocrinol Metab 95(7):3392-3399. https://doi.org/10.1210/jc. 2009-2492

42. Agarwal A, Rehani U, Adlakha V, Kaushik M, Kaushik N (2009) Comparative analysis of the amount of plaque formation and associated gingival inflammation in deciduous, mixed and permanent dentition. Int J Clin Pediatr Dent 2(3):23-26. https://doi.org/10. 5005/jp-journals-10005-1014

43. Emerick JE, Vogt KS (2013) Endocrine manifestations and management of Prader-Willi syndrome. Int J Pediatr Endocrinol 2013(1):14. https://doi.org/10.1186/1687-9856-2013-14
44. Gulati MS, Grewal N, Kaur A (1998) A comparative study of effects of mouth breathing and normal breathing on gingival health in children. J Indian Soc Pedod Prev Dent 16(3):72-83

45. Piva F, Moraes JK, Vieira VR, Silva AER, Hendges RM, Sari GT (2014) Evaluation of the association between indicators of oral health and sociodemographic variables in children with orofacial clinical signs of chronic mouth breathing. Audiol Commun Res 19(3):236242. https://doi.org/10.1590/S2317-64312014000300006

46. Ashley FP, Usiskin LA, Wilson RF, Wagaiyu E (1998) The relationship between irregularity of the incisor teeth, plaque, and gingivitis: a study in a group of schoolchildren aged $11-14$ years. Eur J Orthod 20(1):65-72. https://doi.org/10.1093/ejo/20.1.6

47. Weiler RM, Fisberg M, Barroso AS, Nicolau J, Simi R, Siqueira WL Jr (2006) A study of the influence of mouth-breathing in some parameters of unstimulated and stimulated whole saliva of adolescents. Int J Pediatr Otorhinolaryngol 70(5):799-805. https://doi.org/ 10.1016/j.ijporl.2005.09.008 